\title{
Realistic health care simulation scenario: what is relevant for its design?
}

\section{Cenário em simulação realística em saúde: o que é relevante para a sua elaboração? Escenario en simulación realística en salud: ¿qué es relevante para su diseño?}

How to cite this article:

Kaneko RMU, Lopes MHBM. Realistic health care simulation scenario: what is relevant for its design? Rev Esc Enferm USP. 2019;53:e03453. DOI: http:// dx.doi.org/10.1590/S1980-220X2018015703453

Regina Mayumi Utiyama Kaneko ${ }^{1}$

Maria Helena Baena de Moraes Lopes $^{2}$

\footnotetext{
${ }^{1}$ Universidade Estadual de Campinas, Programa de Pós-Graduação em Enfermagem, Campinas, SP, Brazil.

${ }^{2}$ Universidade Estadual de Campinas, Faculdade de Enfermagem, Campinas, SP, Brazil.
}

\begin{abstract}
We sought to describe the stages of scenario development with emphasis on the most relevant aspects according to the literature and guidelines of The International Nursing Association for Clinical Simulation and Learning and Best Evidence Medical Education, which are discussed and exemplified on the basis of our professional experience. The following stages were described and commented on for scenario design: planning, objectives, simulation structure and format, case description and perception of realism, pre-debriefing, debriefing, evaluation, materials and resources, and pilot test. A scenario design based on good practices involves important elements, and each stage is closely interrelated and interdependent in its creation process.
\end{abstract}

\section{DESCRIPTORS}

Patient Simulation; Simulation Training; Learning; Patient Safety. 


\section{INTRODUCTION}

Patient safety is a global challenge for health and public health organizations. The report "To err is human" presented alarming figures in relation to the number of deaths, around 48,000-98,000 deaths per year ${ }^{(1-2)}$. There are currently an estimated 400,000 deaths from health errors, despite the measures and policies instituted worldwide ${ }^{(3)}$.

To err is human, but to mitigate and prevent the causes which provoke failure is the responsibility of all the levels involved in the health and disease process of the population. In order to improve these results, a realistic health care simulation for the training and graduation of professionals in the area has grown as one of the strategies for developing technical and non-technical skills. Technical skills generally consist of specific procedures in each specialization, and nontechnical skills involve the cognitive and social skills which complement the technique for performing professional practice with quality and safety. Situational awareness, decisionmaking, communication, teamwork, leadership, managing conflict and fatigue are essential skills for activities involving high risks, such as health services ${ }^{(4-5)}$.

In this context, realistic health care simulation has been an explored strategy in teaching laboratories and simulation centers to provide a reflective and transformative environment for developing core competencies for patient-centered care and to achieve the objectives and outcomes proposed in this process of learning and improvement ${ }^{(6-9)}$.

Realistic health care simulation scenarios are an integral and fundamental part of the planning and organization of professional graduate courses, competency and training of health professionals. Some studies demonstrate the importance of a theoretical-practical scenario for elaborating scenarios and its contribution to reach the objectives and to disseminate their use in institutions ${ }^{(10-13)}$. In addition, integrating the strategy into the curricular matrix as a practice in student's development and not as an isolated and complementary component is standardized in the criteria of good practices and reported in studies ${ }^{(14-17)}$.

With the increasing use of this methodology in teaching and health institutions, compliance with stages and a reference to the elaboration are important for designing the scenarios to reach the proposed objectives ${ }^{(14-16)}$.

Scenarios for performing health care simulations are created and based on real-life cases to train technical and non-technical skills ${ }^{(4-5)}$. Incorporating directives which guide scenario design facilitates operationalizing this strategy to all involved (instructor, teacher, operational team of the simulation center, actors and administrative support area), reduces time to create scenarios, standardizes important and essential elements for their elaboration, and consequently for the subsequent discussion with those involved in the debriefing session ${ }^{(7,18-19)}$.

Essential elements for the simulation structure are standardized in good practice criteria for simulations to promote effective learning outcomes and the learning by participants ${ }^{(14-15)}$. Studies show that high fidelity medical simulations facilitate learning when used under the right conditions: feedback during the learning experience, participation by the students in repetitive practices, integration in the curriculum, practice with increasing difficulty level, adaptable to multiple strategies of learning, clinical variations, controlled environment, individualized learning, clarity of objectives and expected results, and validity of simulator realism. These conditions represent the set of goals for elaborating educational programs to maximize the impact of training based on simulation ${ }^{(14-16)}$.

In addition to these criteria, it is necessary to establish a correlation with daily practice and add other elements which are considered important in order to achieve better results with simulation implementation, dissemination and application of the method by professionals. Thus, based on the author's 12 -year professional experience in planning and designing programs with the simulation strategy for the various professional categories (nurses, physicians, physiotherapists, nutritionists, biomedical doctors, administrators, support service professionals and volunteers), this article intended to describe scenario designing stages highlighting the most relevant aspects based on the literature and guidelines of The International Nursing Association for Clinical Simulation and Learning (INACSL) ${ }^{(14)}$ and Best Evidence Medical Education (BEME) ${ }^{(15)}$, and to suggest examples based on our personal experience.

\section{STEPS FOR SCENARIO DESIGN}

\section{PlanNING}

The first criterion consists in surveying the needs, in which evaluating and analyzing the cause of the problem are considered important elements for designing the scenarios, as well as organizational issues, research with those involved, all available data of previous pilot tests (scenario tests), results from knowledge and skills assessments, and guidelines and protocols for determining objectives ${ }^{(14-16)}$.

In addition to these elements and from the experience and practical experience of the authors, an in loco diagnosis is determinant for composing the scenarios which compose a simulation program. It is possible to identify practical aspects of day-to-day life, gaps and opportunities based on real cases, involve the participants and the leadership in this planning to promote better adherence and assist in creating cases according to the reality and level of complexity that the scenario will require for the professional in training or for the student.

Another determining factor is to establish the target audience for the training, because the participants in the scenario could be the professionals who will perform their functions in the current practice, high school, undergraduate or graduate students. For example, if the scenario is intended to encourage nurses to assume their leadership role and make decisions for the nursing team, the target audience for this program must be nurses. In using this criterion, it will be clear to the participants that the scenario represents the daily routine of professional activities, directing the debriefing to discussing the nurse's role as leader of the work team. 
Determining measurable targets to verify the content application addressed in the simulation in the daily practice of the participants can arouse and stimulate research which contributes to knowledge in the area, in addition to being an important outcome metric for the health service.

Selecting instructors according to their knowledge, expertise and simulation experience is essential to the scenario's success. The method requires instructor skills in the role of debriefing facilitator in order to encourage participants to find the best solutions based on the scenario and in accordance with best practices. For example, if the scenario discusses aspects related to difficult airway, the instructor should have this knowledge; if the scenario addresses aspects related to non-verbal communication, a psychologist or nurse with mental health training may be more prepared to observe these aspects and provide discussion focused on the scenario's objective.

Evaluating and analyzing participants' prior knowledge integrates the 'planning' criterion proposed by INACSL ${ }^{(14)}$. In addition to this previous analysis, we suggest strategies which enable transferring the scenario's content after its performance, such as recommending articles related to the topic, institutional indicators related to the scenario, alerts or reminders about procedures that have recurred as inadequate (for example, standard precautions) and others. Describing the theoretical framework references which supported the content is recommended in the scenario preparation form so that the designed scenario is replicated by other facilitators and updated if necessary.

Inviting the leadership of the area in question to participate in planning is essential to legitimize content and engage everyone involved in the success of the program, course or training.

\section{Objective}

The second criterion is related to defining general and measurable objectives for the organizational purposes and specific for measuring the participants' performance. It is recommended that participants be given the objectives prior to implementing the scenario ${ }^{(14-16)}$.

It is important to list both general and specific objectives which are feasible to be incorporated into the scenarios, which are of limited duration. For example, if we determine the objectives to perform urinary catheterization and identify the main complications of catheter permanence, the two objectives cannot be evaluated in the established time frame, which is usually 10 to 15 minutes. This example shows that performing urinary catheterization in a skills lab is more appropriate than in a scenario because it enables each student to individually perform the procedure and each in their own time.

Therefore, in this case we suggest that urinary catheterization is a prerequisite, and the scenario objective and its design be based on catheter permanence with numerous scenarios, such as: safety goals (hand hygiene, patient identification, infection prevention, safety communication); basic care in catheter maintenance in terms of catheter fixation, secretion in the urethral meatus, drainage coloring and volume associated with the clinical situation of the patient; catheter removal and need to confirm patient identification; catheter obstruction; and postoperative hemorrhages of urological surgeries. In addition, behavioral aspects incorporated in these technical scenarios, such as professional presentation, assertive communication, adequate guidelines without the use of technical terms, hospital discharge guidelines and welcoming reception can enrich the discussion at the debriefing time and prepare the professional and student for comprehensive patient care.

Providing goals to participants is recommended by the guidelines ${ }^{(14-16)}$. According to the authors' experience, it is important that the objectives do not guide the scenario's solution, because this would not stimulate clinical reasoning and decision-making. For example, in a scenario involving an emergency situation in cardiology, whose objective is to identify ventricular fibrillation and establish conducts to reverse this condition, instead of defining the objective "Identifying ventricular fibrillation and performing actions to reverse this condition", a better course of action would be to present a more general situation: "Identify the rhythm of collapse and perform the necessary procedures". Thus, the student will need to evaluate the type of rhythm in order to understand, analyze and make a decision, and whether or not to apply the defibrillator. We recommend that students only develop the general objectives and maintain access of the specific objectives only to the facilitator of the scenario.

Realistic health care simulation enables the creation of real-life scenarios, training and developing these skills in simulated and controlled environments which allow for successes and mistakes in the development, which is essential for student learning. Preparing a good scenario can be effective in preventing errors ${ }^{(20-21)}$.

\section{SIMULATION STRUCTURE AND FORMAT}

The third criterion establishes selecting the structure and format of the simulation based on the purpose, theory and modality to develop a simulation based on experience. In this phase of choosing the simulation modality, it is undoubtedly necessary to consider the learner's objectives and evaluation as planned in the course in order to select the most appropriate modality: clinical simulation, in situ simulation, virtual reality, simulation of procedures or hybrid simulation ${ }^{(22)}$. For example, if the objective is to identify latent problems in a hospital unit, the most appropriate modality would be to carry out an in situ simulation because it enables the assessment to be performed in a real environment ${ }^{(23)}$. In a situation experienced by us, in situ simulation enabled to identify delays and inadequacies in service ${ }^{(24)}$.

In the scenario design phase, or more specifically the knowledge of the simulator functionalities, audiovisual resources and adequate equipment are essential for it to be developed to satisfaction; also, if the option is for the simulator or for a standard patient (human patient, actor, teacher or student $)^{(25)}$. Both simulators and standardized patients can compose the technical or behavioral scenarios, or both, and therefore defining these resources in line with their elaboration can increase the scenario's level of complexity and 
extract the full potential of the available resources. They are details which can offer realistic scenarios in their essence, such as determining the positioning of the initial camera and throughout the scene to capture non-verbal expression or performing a procedure by the professional and student; in a standardized patient positioning in a medical appointment, for example, the patient should start the scenario within the office or the professional and student should call them by means of a password, thus providing an environment in which they can introduce themselves, ask the patient's name, offer them a chair to sit down, assist a disabled patient and/or identify risk of fall, in addition to the anamnesis and investigation of problems. Exploring these possibilities takes the scenario closer to reality and enables unparalleled opportunities for further discussion.

Another important point to note is defining the initial number of participants in the scenario and the permission (or not) to include other participants during the course of the scenario. The scenario may include requesting help from a specific professional category (i.e. the doctor) or situations involving more than one professional category, i.e. suspected child abuse case, involving the physician, nurse and the social worker.

In addition to the number of participants, we recommend defining the professional category that will participate in the scenario. According to this selection, a description of the case, the objectives, the evolution, the phrases used by the actors, the debriefing and the checklist present variations according to the expected performance of each professional. These established variations are important to replicate the reality of daily practice and prevent participants, other than the actors, from playing a role during the course of the scenario. When this occurs, comments may arise such as: "I will pretend to be a doctor"; "I'm going to pretend to be a psychologist," indicating that rather than undergoing an experience, they create a role-play.

In Table 1, we exemplify a scenario of communicating bad news (a patient death), involving three distinct professional categories for a better understanding of these variations.

Chart 1 - Example of a case that shows the variations according to the expected performance of each professional - São Paulo, SP, Brazil, 2018.*

\begin{tabular}{|c|c|c|c|}
\hline Professional & Doctor & Nurse & Psychologist \\
\hline Objective & $\begin{array}{l}\text { Report the death of the patient to the } \\
\text { relative. }\end{array}$ & $\begin{array}{l}\text { Evaluate the understanding of the relative } \\
\text { who received the news of the patient's death; } \\
\text { To reaffirm the communication of the } \\
\text { patient's death. }\end{array}$ & $\begin{array}{l}\text { Provide support to the family who received } \\
\text { the news of the patient's death; } \\
\text { To reaffirm the communication of the } \\
\text { patient's death. }\end{array}$ \\
\hline Case & $\begin{array}{l}\text { Patient Maria de Jesus, hospitalized } \\
\text { in the Intensive Care Unit (ICU) } 10 \\
\text { days ago with heart failure, presented } \\
\text { cardiorespiratory arrest (CRP), followed } \\
\text { by death. The daughter, Ana Maria, is } \\
\text { at the reception and is waiting to hear } \\
\text { about her mother. }\end{array}$ & $\begin{array}{l}\text { Patient Maria de Jesus, hospitalized in } \\
\text { the ICU } 10 \text { days ago with Heart Failure, } \\
\text { presented a CRP followed by death. The ICU } \\
\text { doctor reported the death of Maria de Jesus } \\
\text { to her daughter Ana Maria. You are the nurse } \\
\text { who will deliver the patient's belongings to } \\
\text { the family member, who is waiting for you at } \\
\text { the reception. }\end{array}$ & $\begin{array}{l}\text { Patient Maria de Jesus, hospitalized in } \\
\text { the ICU } 10 \text { days ago with Heart Failure, } \\
\text { presented a CRP followed by death. } \\
\text { You have been activated by the nursing } \\
\text { team for psychological support to the family } \\
\text { member at the front desk. At this moment } \\
\text { the family member is out of control and is } \\
\text { emotionally very upset. }\end{array}$ \\
\hline Evolution & $\begin{array}{l}\text { The doctor is expected to perform the } \\
\text { bad news reporting steps. The daughter } \\
\text { (actress) should initially maintain } \\
\text { an optimistic reaction regarding her } \\
\text { mother's state. }\end{array}$ & $\begin{array}{l}\text { The nurse is expected to maintain a } \\
\text { receptive posture and recognize the } \\
\text { daughter's lack of understanding regarding } \\
\text { the death news provided by the doctor and } \\
\text { the communication of the bad news. The } \\
\text { daughter (actress) should initially be very } \\
\text { confused and tell the nurse that she would } \\
\text { like to talk to her mother. }\end{array}$ & $\begin{array}{l}\text { The psychologist is expected to give } \\
\text { emotional support and recognize the } \\
\text { daughter's lack of understanding regarding } \\
\text { the death news provided by the doctor and } \\
\text { the communication of the bad news. The } \\
\text { daughter (actress) should initially be very } \\
\text { anxious and nervous. }\end{array}$ \\
\hline
\end{tabular}

* This example was created and inspired by the care practice and teaching of the authors, including the names of the characters in order to build realism into the scenarios. Any resemblance to real names, people, and real-life facts would have been mere coincidence.

\section{CASE DESCRIPTION AND PERCEPTION OF REALISM}

The case description, the previous history, the starting point of the scenario, the progression of actions, the activities in conducting the scenario, the adequate time for its development and identification of the critical points for monitoring and evaluating the performance are requirements of good practices for simulation, and according to INACSL guidelines ${ }^{(14)}$, should be directly related to the proposed objectives.

In elaborating this case description, we recommend a careful analysis of the information made available to the participant and student, so that the case reading is carried out in line with the reality of the professional. A brief and clear description allows the participant and student to retain this information to start conducting the scenario.
Establishing the beginning of the scenario actions is equally important to situate the student and/or participant. They need to know when to initiate the actions necessary to reach the proposed objectives. We can use some strategies at this stage such as introducing baby crying, a simulated talk requesting help or a speech from the standardized patient complaining about pain and the delay in care. All of these strategies alert the student or participant that they are expected to take action, such as assessing the baby's crying.

The previous history and actions for conducting the scenario should be made available according to the actions performed by the participants and students. For example, in an anaphylaxis scenario, the information 'dipyrone allergy' is only provided when asked. In doing so, we practice communication skills in the anamnesis and exercise clinical 
reasoning for decision-making. Exceptions are expected as essential for conducting the scenario as in the following example, in which more information is necessary since it constitutes past actions to establish the relationship with the current reality: "Maria da Silva performed radical mastectomy due to breast cancer III B with low response to chemotherapy and radiotherapy treatment. She subsequently performed breast reconstruction and has been followed up by the hospital's oncology team. An ovarian carcinoma was identified upon her last visit". In this scenario, prior history is essential for understanding and acting in relation to the new finding: the presence of ovarian carcinoma.

Knowing the reality of the target audience through onsite visits, discussing the training needs with the leadership, and having informal conversations with the professionals who work in the location are actions which contribute to creating training programs. These actions facilitate the case description, in addition to promoting integration and engagement of all involved.

The complete description with all the information in the scenario is a sine qua non for the simulation and also includes a progression of changes in the parameters and actions supported by the several previously selected technologies ${ }^{(14,16)}$. We emphasize that the details must be valued in order to maintain the realism of the strategy; for example, to start the scenario with electrocardiographic monitoring cables connected (or not) to the simulator. This analysis is important when we correlate it with the scenario description: intensive care unit; nursing ward; patient in the admission process to the unit or an already hospitalized patient. Another frequent example in the simulations is whether the crash cart is within the scenario or the participant should realize the need, call for help, and request a crash cart to the scene location. The description and progression change depending on this analysis, and the scenario provides realism for developing activities.

Regardless of the feature chosen, the scenario description should provide data for everyone involved in its performance. As the scenario progression depends on the actions carried out by the participants, the importance of this description, including elaborating phrases for appropriate (or inadequate) attitudes, is emphasized in order to direct the facilitators, the simulation center staff and the actors. It is recommended to standardize some speeches during the scenario in order to meet the simulation objectives.

In the case of the scenario with actors, it is advisable to provide subsidies so they incorporate the character, because even though some lines may be improvised, they must meet the pre-established script to provide realism in the scenario and reach the defined objectives. The costumes, the physical constitution, the language, and the psychological condition of the actor are elements which help them create and stage their character. Another crucial element is to stipulate how much the actor should remain in the initially created script or whether an alternative (also pre-established) will be followed according to the student's and/or health professional's performance. An example is given in Chart 2.

Chart 2 - Example of a scenario with actors - São Paulo, SP, Brazil, 2018.*

\begin{tabular}{|c|c|}
\hline \multicolumn{2}{|c|}{$\begin{array}{l}\text { Case: Maria da Silva, } 40 \text { years old, obese, executive, went to the emergency room for care. She has an important meeting to present a project of } \\
\text { great relevance to her company. }\end{array}$} \\
\hline \multicolumn{2}{|c|}{ Physical profile: obese, age range $35-40$ years old. } \\
\hline \multicolumn{2}{|c|}{ Psychological profile: anxious, worried and upset. } \\
\hline \multicolumn{2}{|c|}{$\begin{array}{l}\text { Social profile: MBA (Master in Business Administration), works in a multinational institution and has an important meeting to present a project of } \\
\text { relevance to the company and to her professional career. }\end{array}$} \\
\hline $\begin{array}{l}\text { Attitude A: The actress will initially be anxious, worried and upset } \\
\text { because she was referred to the emergency room, accompanied by her } \\
\text { husband. If the volunteer performs assertive communication (a verbal } \\
\text { and non-verbal communication process, speaks truthfully without } \\
\text { making judgments or going off topic, aiming to convey information } \\
\text { clearly and safely), the actress agrees to be examined and to continue } \\
\text { with the treatment. }\end{array}$ & $\begin{array}{l}\text { Attitude B: The actress will initially be anxious, worried and upset } \\
\text { because she was referred to the emergency room, accompanied by her } \\
\text { husband. If the volunteer does not perform assertive communication (an } \\
\text { improper verbal and non-verbal communication process, not speaking } \\
\text { truthfully, making judgments, not transmitting information clearly and } \\
\text { safely), the actress will maintain her initial status and will not agree to be } \\
\text { examined or to do treatment. }\end{array}$ \\
\hline $\begin{array}{l}\text { Phrases that can be used (examples): } \\
\text { "My husband brought me for an appointment, I have nothing, it's just a } \\
\text { little pain in the chest. It went away!". } \\
\text { "Please, can you do the appointment as quickly as possible?". } \\
\text { "I understand, in case of changes in the exams, I will have to stay...". }\end{array}$ & $\begin{array}{c}\text { Phrases that can be used (examples): } \\
\text { "Who are you? I'm here in the emergency room because my husband } \\
\text { made me!". } \\
\text { "You can't keep me here, I have a very important meeting!". } \\
\text { "You have no idea, of course you don't!". }\end{array}$ \\
\hline
\end{tabular}

*This example was created and inspired by the care practice and teaching of the authors, including the names of the characters in order to build realism into the scenarios. Any resemblance to real names, people, and real-life facts would have been mere coincidence.

Another critical point is planning all the material resources necessary for the scenario reality: equipment, materials, patient's clothing, medical records and even simpler elements such as paper tissues and jugs with water and glasses for behavioral scenarios of bad news with the purpose of comfort.
It is important to consider that some routines established in some simulation centers to preserve the durability of the simulators, such as wearing gloves at all times and not performing procedures in high and medium reliable simulators in order not to damage them may induce failure to perform the procedure or lack of discernment as to the 
need for certain actions in professional practice, for example the absence of criteria for using gloves as individual protection, the need for sterile gloves for aseptic procedures and hand hygiene before and after the procedures.

\section{Pre-Debriefing OR Briefing}

It is considered good practice to start the simulation with pre-debriefing, which means with a presentation of the participants' expectations and directions about the simulated environment and its resources ${ }^{(14-16)}$. It should be part of the training program plan.

The pre-debriefing should be standardized through training the simulation center's facilitators and staff. It should make clear to practitioners and students what simulation strategy to employ and what resources will be available. This contributes to establishing communication and trust between the participants and giving more safety to the volunteers, since they will expose themselves to the group during the simulation and debriefing after the end of the scenario.

Creating a supportive and interactive environment depends on the ability of the facilitator who, in being integrated with the realistic simulation methodology, understands the error as an opportunity for improvement and exercises their role as facilitator of the group. Elaborating instructional videos on simulation, performing presentation dynamics of each participant in their group ("icebreaker" techniques) and other strategies contribute to greater interaction among the group, reducing resistance to participation in the activity.

As in aviation, in which the pilot is trained with a flight simulator which corresponds to the airplane to be piloted, the briefing is intended to recall processes, define the flight plan, collect relevant information to the activities in the simulator ${ }^{(26)}$.

According to the target audience in the health area (for example, professionals who do not work at the bedside), it is interesting to do the briefing to remember algorithms and processes. An example of this is a patient scenario with acute myocardial infarction who evolves to ventricular fibrillation (VF) and defibrillator failure occurs, and it has the objective of discussing aspects related to technovigilance for health institution managers. In this case, a briefing of the VF algorithm is recommended because the scenario is built to sensitize managers in all aspects involving hospital equipment, from their acquisition, standardization, training, preventive maintenance and impact on patient care.

\section{DeBRIEFING}

It is a criterion of good practices in simulation to perform the debriefing or feedback by trained facilitators in the technique ${ }^{(27)}$.

Creating a roadmap for the facilitator with the objectives, the scenario's critical points and questions which can guide the discussion allows it to be led by facilitators who did not participate in creating the scenario, thereby enabling its reproducibility.
The actor's feedback to the participant at the end of the scenario with comments on how they felt in the role they played is important for the student's or the professional's training.

\section{Evaluation}

The course evaluation by the participants, facilitators and support team in the simulation is another criterion recommended by INACSL ${ }^{(14)}$, being indisputably fundamental to guarantee the continuous improvement of the simulation processes and results. An evaluation of the participant by assessment instruments is a common practice in institutions, however the facilitator's and the simulation team's performance, in addition to the items evaluated by the instruments in general deserve attention in relation to the specific aspects of the methodology. In this case, it is possible to discuss and increment improvements by reviewing the activities on video, promoting a debriefing of the debriefing and the facilitator's performance.

In terms of participant evaluation, the Objective Structured Clinical Examination (OSCE) is a tool used to examine clinical competencies in a simulated environment. Studies also report expanding its use for improving competencies and knowledge application in simulated environments ${ }^{(28-29)}$.

\section{Materials And Resources}

An analysis, selection and elaboration of materials and resources for the professional and student are required as a good practice in order to ensure the learning outcome according to the proposed objectives ${ }^{(14-16)}$.

\section{PILOT TEST}

An elaborated scenario pilot test is recommended by the INACSL guidelines ${ }^{(14)}$ with the objective of guaranteeing the learning experience in the simulation, identifying and correcting faults and allowing the evaluation of all the selected tools.

An interesting strategy is conducting the pilot test so that any unforeseen situations are evidenced. Thus, it is possible to assess the clarity of the scenario description, and the need for any additional information. It is important that the professional or student participating in the pilot test is part of the target audience in the scenario.

\section{FINAL CONSIDERATIONS}

A scenario design based on good practices involves important elements, and each stage is interconnected and interdependent in its creation process.

Validated instruments which guide elaboration of scenarios in health care simulations include established criteria for good practices, and could disseminate this important methodology, thereby enabling its reproducibility in health care and teaching institutions and favor its more frequent implementation, providing a learning process to be incorporated into the daily practice of professionals and students, and consequently ensuring safe care for patients. 


\section{RESUMO}

Buscou-se descrever as etapas de elaboração de cenários, com destaque para os aspectos mais relevantes, segundo a literatura e as diretrizes da The International Nursing Association for Clinical Simulation and Learning e da Best Evidence Medical Education, as quais são discutidas e exemplificadas com base em nossa experiência profissional. Foram descritas e comentadas as seguintes etapas para elaboração de cenários: planejamento, objetivos, estrutura e formato da simulação, descrição do caso e percepção do realismo, pre-debriefing, debriefing, avaliação, materiais e recursos e piloto. A elaboração do cenário baseada em boas práticas envolve elementos importantes, e cada etapa está intimamente interligada e interdependente no seu processo de criação.

\section{DESCRITORES}

Simulação de Paciente; Treinamento por Simulação; Aprendizagem; Segurança do Paciente.

\section{RESUMEN}

Se buscó describir las etapas de confección de escenarios, con énfasis en los aspectos más relevantes, según la literatura y las directrices de la The International Nursing Association and Learning y de la Best Evidence Medical Education, las que se discuten y ejemplifican de acuerdo con nuestra experiencia profesional. Fueron descritas y comentadas las siguientes etapas para el diseño de escenarios: planificación, objetivos, estructura y formato de la simulación, descripción del caso y percepción del realismo, predebriefing, debriefing, evaluación, materiales y recursos y piloto. El diseño del escenario basado en buenas prácticas abarca elementos importantes, y cada etapa está íntimamente interconectada e interdependiente en su proceso de creación.

\section{DESCRIPTORES}

Simulación de Paciente; Entrenamiento Simulado; Aprendizaje; Seguridad del Paciente.

\section{REFERENCES}

1. Kohn LT, Corrigan JM, Donaldson MS, editors. To err is human: building a safer health system. Washington: Institute of Medicine, Committee on Quality of Health Care in America, National Academies; 2000.

2. Leape LL, Berwick DM. Five years after to err is human: what have we learned? JAMA. 2005;293(19):2384-90.

3. Makary MA, Daniel M. Medical error-the third leading cause of death in the US. BMJ. 2016;353:i2139.

4. Flin R, $\mathrm{O}^{\prime}$ Connor P, Crichton M. Safety at the sharp end: a guide to non-techinical skills. Surrey: Ashgate; 2008.

5. Gordon M, Baker P, Catchpole K, Darbyshire D, Schocken D. Devising a consensus definition and framework for non-technical skills in healthcare to support educational design: a modified Delphi study. Med Teach. 2015;37(6):572-7. DOI: 10.3109/0142159X.2014.959910

6. Berragan L. Simulation: an effective pedagogical approach for nursing? Nurse Educ Today. 2011;31(7):660-3. DOI: 10.1016/j.nedt.2011.01.019

7. Teixeira CRS, Pereira MCA, Kusumota L, Gaioso VP, Mello CL, Carvalho EC. Evaluation of nursing students about learning with clinical simulation. Rev Bras Enferm. 2015;68(2):311-9. DOI: http://dx.doi.org/10.1590/0034-7167.2015680218i

8. Tan K, Chong MC, Subramaniam P, Wong LP.The effectiveness of outcome based education on the competencies of nursing students: a systematic review. Nurse Educ Today. 2018;64:180-9. DOI: https://doi.org/10.1016/j.nedt.2017.12.030

9. Harvey R, Mellanby E, Dearden E, Medjoub K, Edgar S. Developing non-technical ward- round skills. Clin Teach. 2015;12(5):336-40. DOI: $10.1111 /$ tct. 12344

10. Garbuio DC, Oliveira ARS, Kameo SY, Melo ES, Dalri MCB, Carvalho EC. Clinical simulation in nursing: experience report on the construction of a scenario. J Nurs UFPE on line. 2016;10(8):3149-55. DOI: https://doi.org/10.5205/1981-8963-v10i8a11388p3149-3155-2016

11. Fabri RP, Mazzo A, Martins JCA, Fonseca AS, Pedersoli CE, Miranda FBG, et al. Development of a theoretical-practical script for clinical simulation. Rev Esc Enferm USP. 2017;51:e03218. DOI: 10.1590/S1980-220X2016265103218

12. Neves FF, Pazin-Filho A. Construindo cenários de simulação: pérolas e armadilhas. Sci Med. 2018;28(1):ID28579. DOI: 10.15448/19806108.2018.1.28579

13. Banbini D.Writing a simulation scenario: a step-by-step guide. AACN Adv Crit Care. 2016;27(1):62-70. DOI: 10.4037/aacnacc2016986

14. INACSL Standards Committee. INACSL standards of best practice: simulation ${ }^{\mathrm{SM}}$ simulation design. Clin Simul Nurs [Internet]. 2016 [cited 2018 Feb 12];12(5 Suppl):S5-S12. Available from: https://www.inacsl.org/INACSL/document-server/?cfp=INACSL/assets/File/public/ standards/SOBPEnglishCombo.pdf

15. Issenberg SB, McGaghie WC, Petrusa ER, Lee Gordon D, Scalese RJ. Features and uses of high-fidelity medical simulations that lead to effective learning: a BEME systematic review. Med Teach. 2005;27(1):10-28.

16. Motola I, Devine LA, Chung HS, Sullivan JE, Issenberg SB. Simulation in healthcare education: a best evidence practical guide. AMEE Guide No. 82. Med Teach. 2013;35(10):e1511-30. DOI: 10.3109/0142159X.2013.818632

17. Escudero E, Avendaño Ben-Azul M, Domínguez Cancino K. Simulación clínica y seguridad del paciente: integración en el currículo de enfermería. Sci Med. 2018;28(1):ID28853. DOI: http://doi.org/10.15448/1980-6108.2018.1.28853

18. Almeida RGS, Mazzo A, Martins JCA, Coutinho VRD, Jorge BM, Mendes IAC. Validation to Portuguese of the Debriefing Experience Scale. Rev Bras Enferm [Internet]. 2016;69(4):658-64. DOI: http://dx.doi.org/10.1590/0034-7167.2016690413i

19. Palaganas JC, Fey M, Simon R. Structured debriefing in simulation-based education. AACN Adv Crit Care. 2016;27(1):78-85. DOI: 10.4037/aacnacc2016328

20. Sarfati L, Ranchon F, Vantard N, Schwiertz V, Larbre V, Parat S, et al. Human-simulation-based learning to prevent medication error: a systematic review. J Eval Clin Pract. 2019;25(1):11-20. DOI: 10.1111/jep.12883

21. Ziv A, Ben-David S, Ziv M. Simulation based medical education: an opportunity to learn from errors. Med Teach. 2005;27(3):193-9. 
22. Pazin-Filho A, Scarpelini S. Simulação: definição. Medicina (Ribeirão Preto) 2007;40 (2):162-6.

23. Patterson MD, Geis GL, Falcone RA, LeMaster T, Wears RL. In situ simulation: detection of safety threats and teamwork training in a high risk emergency department. BMJ Qual Saf. 2013;22(6):468-77. DOI: 10.1136/bmjqs-2012-000942

24. Kaneko RM, Couto TB, Coelho MM, Taneno AK, Barduzzi NN, Barreto JK, et al. Simulação in situ, uma metodologia de treinamento multidisciplinar para identificar oportunidades de melhoria na segurança do paciente em uma unidade de alto risco. Rev Bras Educ Med [Internet]. 2015 [citado 2018 fev 12];39(2):286-93. Disponível em: http://dx.doi.org/10.1590/1981-52712015v39n2e00242014

25. Barrows HS. An overview of the uses of standardized patients for teaching and evaluating clinical skills. AAMC. Acad Med. 1993;68(6):443-51.

26. McGreevy JM, Otten TD. Briefing and debriefing in the operating room using fighter pilot crew resource management. J Am Coll Surg. 2007;205(1):169-76.

27. Fanning RM, Gaba DM. The role of debriefing in simulation-based learning. Simul Healthc. 2007;2(2):115-25. DOI: 10.1097/ SIH.0b013e3180315539

28. Nulty DD, Mitchell ML, Jeffrey CA, Henderson A, Groves M. Best practice guidelines for use of OSCEs: maximising value for student learning. Nurse Educ Today. 2011;31(2):145-51. DOI: 10.1016/j.nedt.2010.05.006

29. Aronowitz T, Aronowitz S, Mardin-Small J, Kim B. Using Objective Structured Clinical Examination (OSCE): as education in advanced practice registered nursing education. J Prof Nurs. 2017;33(2):119-125. DOI: 10.1016/j.profnurs.2016.06.003 